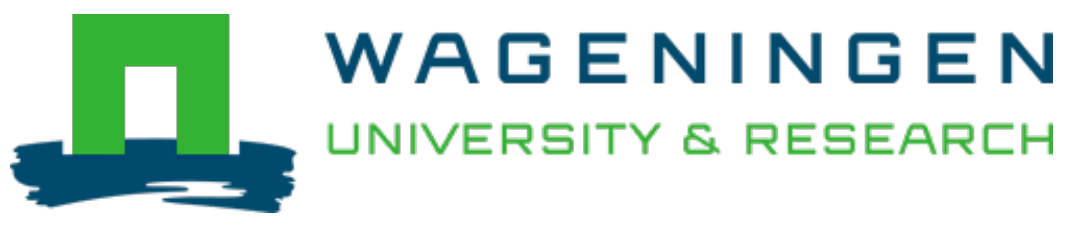

\title{
Injustice in Food-Related Public Health Problems: A Matter of Corporate Responsibility
}

Business Ethics Quarterly

Tempels, Tjidde; Blok, Vincent; Verweij, Marcel

https://doi.org/10.1017/beq.2019.41

This article is made publicly available in the institutional repository of Wageningen University and Research, under the terms of article $25 \mathrm{fa}$ of the Dutch Copyright Act, also known as the Amendment Taverne. This has been done with explicit consent by the author.

Article 25 fa states that the author of a short scientific work funded either wholly or partially by Dutch public funds is entitled to make that work publicly available for no consideration following a reasonable period of time after the work was first published, provided that clear reference is made to the source of the first publication of the work.

This publication is distributed under The Association of Universities in the Netherlands (VSNU) 'Article $25 \mathrm{fa}$ implementation' project. In this project research outputs of researchers employed by Dutch Universities that comply with the legal requirements of Article $25 \mathrm{fa}$ of the Dutch Copyright Act are distributed online and free of cost or other barriers in institutional repositories. Research outputs are distributed six months after their first online publication in the original published version and with proper attribution to the source of the original publication.

You are permitted to download and use the publication for personal purposes. All rights remain with the author(s) and / or copyright owner(s) of this work. Any use of the publication or parts of it other than authorised under article $25 \mathrm{fa}$ of the Dutch Copyright act is prohibited. Wageningen University \& Research and the author(s) of this publication shall not be held responsible or liable for any damages resulting from your (re)use of this publication.

For questions regarding the public availability of this article please contact openscience.library@,wur.nl 


\title{
Injustice in Food-Related Public Health Problems: A Matter of Corporate Responsibility
}

\author{
Tjidde Tempels \\ Radboud University \\ Wageningen University \\ Vincent Blok \\ Marcel Verweij \\ Wageningen University
}

\begin{abstract}
The responsibility of the food and beverage industry for noncommunicable diseases is a controversial topic. Public health scholars identify the food and beverage industry as one of the main contributors to the rise of these diseases. We argue that aside from moral duties like not doing harm and respecting consumer autonomy, the food industry also has a responsibility for addressing the structural injustices involved in food-related health problems. Drawing on the work of Iris Marion Young, this article first shows how food-related public health problems can be understood as structural injustices. Second, it makes clear how the industry is sustaining these health injustices, and that due to this connection, corporate actors share responsibility for addressing food-related health problems. Finally, three criteria (capacity, benefit, and vulnerability) are discussed as grounds for attributing responsibility, allowing for further specification on what taking responsibility for food-related health problems can entail in corporate practice.
\end{abstract}

KEY WORDS: corporate responsibility, public health, food and beverage industry, structural injustice, noncommunicable diseases

T $\mathrm{n}$ the public health debate, the food and beverage industry ${ }^{1}$ is often portrayed as 1 one of the main contributors to the rise of noncommunicable diseases (NCDs), such as obesity and type 2 diabetes. Authors critical of contemporary global food systems point out that this industry, through its products, marketing, and lobbying practices, sustains and furthers the prevalence and severity of NCDs. They argue that in order to halt these developments and ensure citizens have access to adequate diets, governments should curb the impact the industry has on food-related public

\footnotetext{
${ }^{1}$ We assess the responsibility of corporate actors in the food and beverage industry, but the terms 'food industry' and 'food and beverage industry' will be used interchangeably. 
health issues ${ }^{2}$ by means of additional regulation (Moss 2013; Nestle 2015; Stuckler and Nestle 2012).

Although the industry plays an important part in the constitution of public health problems, the central claim of those critical of the food and beverage industry-that businesses are the main culprits in the rise of obesity and type 2 diabetes - disregards the complexity of consumption-related harms. There are many social determinants and societal actors that shape and influence public health problems: people's genetic makeup, the food choices of consumers, and social and cultural eating norms, as well as (the absence of) governmental regulation, all contribute to the rise of these diseases. Still, this does not mean that firms can be excused from responsibility for food-related public health problems, and that responsibility for public health should be understood as a mere personal or governmental responsibility (cf. Epstein 2004). Rather, we can wonder what the responsibilities of the food industry are for these public health problems.

The question of corporate responsibility for such mediated harms is something that is being actively discussed in the field of business ethics (Arnold 2013; Bowie 1999; Freeman 2002; Friedman 2009). Often, however, these discussions focus on the kind of behavior food firms should not engage in (e.g., the sale of unsafe products, deception and manipulation of consumers to eat unhealthy, or the lobby against public health regulation), yet relatively little is said on the possible positive responsibilities food firms could have on public health (Nestle 2013, 2015; Tempels, Verweij, and Blok 2017).

In this article, we argue that aside from moral responsibilities like not doing harm and respecting consumer autonomy, the food industry also has a responsibility for addressing the structural injustices involved in food-related health problems (cf. Arnold 2013). We add to the debate on corporate responsibility by exploring what responsibilities food and beverage firms could have for addressing these kinds of problems, while also assessing what taking this responsibility could entail in corporate practice (cf. Brenkert 1998; Schrempf 2014).

We first discuss how corporate responsibility for consumption-related harms is frequently understood in debates on business ethics. While liability and governmental approaches to public health are viable when assessing what actions of food firms are morally and legally wrong, we hold that these approaches overlook an important ethical issue, namely the structural injustices involved in food-related health harms and the role food firms play in the construction of these injustices. Drawing on the work of Iris Marion Young, we argue that dealing with structural injustices necessitates a forward-looking guiltless responsibility that flows from what she calls a 'social connection model of responsibility' (Young 2011). On the basis of this approach, responsibility for the structural injustices in food-related

\footnotetext{
2 In this article, we focus specifically on public health issues that are often associated with food and beverage consumption (e.g., NCDs, such as type 2 diabetes, obesity, and heart failure). Henceforth, we will refer to these as food-related public health issues.
} 
health problems can be conceived as a shared responsibility between a plurality of connected actors. We show how actors in the food industry are connected to this problem and why this implies a corporate responsibility to address these injustices.

We subsequently discuss what discharging this responsibility could mean in corporate practice. Although Young's theory is helpful in understanding structural injustices, her theory provides limited guidance on what taking on this responsibility involves in practice. Simply stating that all actors have a shared responsibility will not help to mitigate structural injustice, for if all are responsible, then none are likely to feel accountable. Actors might leave other actors to take responsibility and shirk their own responsibilities. To see how responsibility for the structural injustices in food-related public health issues could be attributed to different corporate actors, we propose additional normative criteria for assigning responsibility following Miller (2001, 2012) and Owen (2013).

By showing that public health problems feature structural injustices, this article creates room for a more inclusive approach to alleviating food-related public health issues. By virtue of being connected to structural health injustices, food firms have a shared responsibility to prevent and mitigate food-related public health issues. The degree of corporate responsibility attributed is context dependent: it matters what kind of consumer groups the industry is dealing with, what capacity the company has, and what benefits it derives from structural injustices. Although companies can do many things to take responsibility for public health (develop new, healthier products; lobby for stricter regulation), given that structural injustices predominantly concern the most vulnerable groups in society and the means of firms will necessary be limited compared to the demands of responsibility, prioritization is needed. This implies that we can, for instance, expect companies to develop new, more healthful products that low-income consumers are likely to purchase, use behavioral nudging in supermarkets to steer people toward healthier choices, give coupons for healthy food to people receiving public support, and sponsor athletic activities in vulnerable neighborhoods.

The article is organized as follows: in section 1 we briefly sketch how corporate responsibility for health in the food industry can be understood and how this misses out on the injustices involved in food-related public health issues. In section 2 Young's conception of structural injustice is discussed to show that food-related public health issues can be understood as structural injustices and it is made clear how the industry is connected to this (Young 2001, 2011; McKeown 2014). In section 3 we briefly set out the social connection model of responsibility and discuss why connection to structural injustice implies a responsibility to address these injustices. In addition, we introduce criteria for assigning corporate responsibility for food-related public health issues, which help to illustrate what kind of actions this could imply for different actors in the food industry (Butt 2007; Miller 2012). The theoretical and practical implications of corporate responsibility for structural injustices are set out in section 4, and we conclude the article in section 5 by briefly discussing the key contributions of our approach to the fields of business ethics and public health ethics. 


\section{ON CORPORATE RESPONSIBILITY AND PUBLIC HEALTH PROBLEMS}

Taking action for public health issues has long been perceived as a traditional governmental responsibility. Programs that aimed to protect and promote the health of the population, like sanitation programs, pollution control, and vaccination, have generally been conceived as a public policy issue on which different types of governmental organizations would take action (Childress et al. 2002; Gostin 2008; Rothstein 2002). Over the years, the focus on governmental responsibility has become contested in the wake of the increase of so-called lifestyle-related health problems, such as obesity, type 2 diabetes, and cardiac diseases. The fact that these diseases are closely related to individual behavior and consumption leads to the question of whether the effects of these health-damaging practices should be understood as a personal responsibility rather than as a governmental responsibility. While libertarian scholars and politicians stress people's personal responsibility for health deficiencies that are due to unhealthy nutrition, public health scholars point to how social conditions influence these choices and how the food and beverage industry is creating an obesogenic environment and is contributing to these diseases (Nestle 2013; Brownell and Warner 2009).

Large players in the food industry are being criticized for both their business activities (development and marketing of unhealthy products, deceptive marketing) and their political activities (lobbying against public health regulations, pushing additional agricultural subsidies), both of which impact public health (cf. Dorfman et al. 2012; Fields 2004; Franck, Grandi, and Eisenberg 2013; Nestle 2015; Shelley, Ogedegbe, and Elbel 2014; Smith 2012; Walters 2015). Some public health professionals even refer to obesity and type 2 diabetes as industrial epidemics that are "emerging from the commercialization of potentially health damaging products" (Gilmore, Savell, and Collin 2011, 2). A majority of public health scholars, therefore, argue that the negative impact of 'Big Food' should be curbed through governmental regulation of the industry, for instance, through laws regulating lobbying and marketing, implementing product bans, and increasing taxes on unhealthy food products (Gilmore, Savell, and Collin 2011; Nestle 2015; Stuckler et al. 2012; Yoon and Lam 2013).

\subsection{Moving Beyond Governmental Responsibility for Public Health}

Although we agree that there is ample need for the government to regulate the food industry, there are empirical, pragmatic, and normative reasons to at least consider the possibility of what corporate responsibility for public health might entail. First of all, several businesses are already engaging in activities that could contribute to public health. Although one might argue that these efforts are poorly motivated or insufficient (Stuckler et al. 2012; Elliott 2015), we should not turn a blind eye to the positive developments that are taking place. An increasing number of companies are developing healthier food products (products that contain less salt, sugar, and fat), voluntarily applying front-of-pack nutrition labels (such as the traffic light food label in the UK), and participating in (public-) private partnerships that seek to stimulate healthier behavior (for instance, aimed at sponsoring sport events or improving 
education about nutrition). The potentially positive impact of these efforts should not be overlooked (Tempels, Verweij, and Blok 2017)

Second, a focus on governmental action regarding public health fails to take into account the practical complexity of NCDs. These diseases are embedded in social contexts that are influenced by many different determinants and actors, which governments cannot address on their own. While governmental intervention regarding public health (education, regulation) is crucial for reducing food-related health problems, it is unlikely to be the magic ingredient required for dealing with these problems, as governments can be unable or unwilling to address these problems. Even when they do intervene, the public health gains remain limited. $\mathrm{Ng}$ and colleagues $(2014,766)$ report that "not only is obesity increasing, but no national success stories have been reported in the past 33 years" and argue that coordinated action is crucial to reverse this trend. For that reason, some health ethicists suggest a pragmatic position - that responsibility for public health should not be seen as solely a governmental responsibility but as a collective action that is needed to promote and protect the health of the population and that also involves businesses (Verweij 2014; Verweij and Dawson 2009, 2019).

Finally, having corporate social responsibility (CSR) programs for public health makes sense if we tie this in with the normative debate in business ethics on (political) CSR. The debate suggests that corporate actors have societal and environmental responsibilities in addition to their traditional economic responsibilities. In practice, this can even entail doing those tasks that had traditionally been conceived to be classic governmental responsibilities, like managing environmental governance or addressing public health issues (Heikkurinen and Mäkinen 2018; Scherer et al. 2016; Tempels, Blok, and Verweij 2017). Yet, the question, of course, is what this responsibility consists of and what it would entail within the context of the food and beverage industry in regard to public health.

\subsection{Ordinary Morality and Corporate (Ir)responsibility}

Whether there are corporate responsibilities for individual and collective harms caused by firms, and what the scope of these kinds of responsibilities would be, is at the heart of debates in business ethics. According Hsieh (2017), firms should adhere to the principles of ordinary morality. This means that firms should live up to the principle of nonmaleficence and the principle of respect for autonomy in both market and nonmarket activities, and that companies can be considered morally blameworthy at the moment they fail to live up these principles. This can refer to moral wrongs, for instance, when a firm knowingly and willingly harms a consumer, as well as to moral negligence, such as when a firm is expected to inform a consumer about the relevant properties of a product, but fails to do so (cf. Ebejer and Morden 1988; Hasnas 2009; Sher 2011). In discussions on corporate irresponsibility in sales and marketing in the food and beverage industry, these principles of ordinary morality are frequently highlighted as key moral rules to which firms need to live up to in their daily operations. While public health ethicists like Barnhill et al. (2014) put forth that there is no a priori wrong in selling unhealthy food products, there are 
certain moral standards firms need to adhere to when producing, marketing, and selling these products (Barnhill et al. 2014; Sunstein 2016). From this it follows, for instance, that firms could have a moral obligation to refrain from marketing unhealthy products to children and that there are moral reasons to reconsider the way such products are promoted to adults. Not living up to these rules to not cause harm and respect consumer autonomy can be understood as irresponsible and morally blameworthy behavior (cf. Barnhill 2016; Beauchamp, Hare, and Biederman 1984; Carsons 2009; Crisp 1987).

In a well-ordered society, several of these minimal moral rules that flow from ordinary morality are codified in laws and regulation. Many governments set standards and provide rules that structure the market and regulate corporate behavior. For the food and beverage industry, there are, for instance, safety standards for food products, laws that ban the sales of several harmful products, and rules limiting certain manipulative marketing practices (cf. Buzby and Frenzen 1999).

\subsection{A Wider Corporate Responsibility to Prevent and Mitigate Food-Related Health Harms?}

The above brief overview makes clear that food firms have various moral and legal responsibilities with regard to public health. Firms have a legal responsibility to comply with food laws and governmental standard setting and are not to produce and sell products that are unsafe, while simultaneously having the moral responsibility to strive not to harm their consumers (for instance, by marketing unsafe foods ${ }^{3}$ ) or by disrespecting consumer autonomy (for example, by deceiving consumers into eating unhealthy products). If firms fail to adhere to these legal rules or live up to these basic principles of morality, they can be legitimately blamed or held (strictly) liable. However, even though there are clear corporate responsibilities in regard to health harms, this remains a rather minimalist approach to corporate responsibility. It stipulates what firms should not do, but tells us little about what kind of positive actions might be required to address food-related health problems.

Now, some libertarian scholars might argue this is not a problem, or at least not a problem food firms should be concerned with (cf. Epstein 2004; Hasnas 2009; Palmer and Hedberg 2013). When corporate actors account for their legal obligations and respect ordinary morality, this is where the buck stops when it comes to corporate responsibility for health. In a free market, competition, supply, and demand are central. If there is a great demand for tasty food products among

\footnotetext{
${ }^{3}$ In reference to Barnhill et al. (2014), we make a distinction between unsafe and unhealthy foods products. Unhealthy food products significantly increase the risk of food-related health harms (NCDs) but do not pose an immediate harm to health and whose risk-attributing components are food substances (e.g., salt, sugar, fat). This can be contrasted with unsafe food products, namely foods that pose a risk of direct harm (poisonous foods), pose a risk of harm at any level of consumption (disease-carrying food), or where the risk is induced through nonfood substances (e.g., foods containing mercury) (Barnhill et al. 2014, 192-93).
} 
consumers, food-producing businesses should provide such products, and consumers should be free to decide what they want to eat or drink (cf. Hasnas 2009). If the product tastes so good that it entices the consumer to continue eating, it is questionable whether this is something the company should be blamed or held accountable for; instead, it seems to be doing exactly what the market expects it to do. Ultimately, the responsibility for eating specific unhealthy products lies with consumers themselves. Bearing this in mind, it is problematic to hold a law-abiding candy store or fast-food chain responsible for taking action to prevent heart problems of their returning customers.

This kind of reasoning also returns in legal suits against the food industry in regards to health harms, for instance, in the well-known case of Pelman v. McDonald's in the United States (Adams 2005). In this case, Ashley Pelman and Jazlyn Bradley, who suffered from obesity and weight-related health complications, argued that their heavily fast-food-based diet contributed to their dire health situations, and that McDonald's should bear responsibility for this. The court, however, held that it was a well-known fact that fast-food products contain high levels of salt, sugar, and fat, and that consumption of large quantities of these ingredients could have detrimental health effects. It went on to say that provided that consumers were sufficiently knowledgeable or were able to obtain the relevant knowledge, they could freely exercise their choice, and hence the producers should not be held liable (Adams 2005; Wicker 2015). Hence, if firms meet the legal standards for selling unhealthy products and respect consumer autonomy, then the possible negative results of unhealthy consumption cannot be the responsibility of the firm. In those cases, it is the consumer who willingly and knowingly chooses to consume unhealthy food, and as such the consequences of this decision are also her responsibility. The responsibility of the food and beverage companies seems to be restricted by a commitment to the notion of consumer autonomy.

Yet, we hold such a limited interpretation of corporate responsibility that misses out on how social processes structure and constrain people's lives and how this can lead to harms. In her work on responsibility for justice, political philosopher Iris Marion Young put forth that these social processes can lead to injustices, and thateven though this is the result of a combination of societal processes and of different actors operating together-we should consider what responsibilities actors have for addressing these injustices (Young 2001, 2004, 2011).

While Young's work does not focus on public health or corporate responsibility in particular, we think her idea of structural injustice is helpful in rethinking the food industry's responsibility for the global obesity epidemic and other foodrelated public health issues. Young's notions of social processes and structure are relevant in understanding the possible injustices in the spread of NCDs, as social structures constrain people's abilities to make healthier choices or live healthier lives (Stronks et al. 1996; Mackenbach et al. 2016; Haverkamp, Verweij, and Stronks 2018). Laying bare the structural injustices involved in the spread of NCDs, in turn, allows us to assess how the food and beverage industry is connected to this and how this might ground a more positive corporate responsibility response to these injustices. 
In the next section, we will set out why food-related health harms involve structural injustices and how corporate actors in the food and beverage industry are connected to this.

\section{STRUCTURAL INJUSTICE, HEALTH DEPRIVATION, AND THE ROLE OF THE FOOD INDUSTRY}

On the basis of Young's work on social processes and structural injustice (2001, 2011), we illustrate how social structures shape and constrain lives of people and show how the (increasingly) unequal distribution of food-related public health harms can be conceived as structural injustices. This creates room to think about which groups are facing these injustices and, subsequently, how the food industry is connected to this. To start this reflection, it is necessary to explain how Young understands structure and structural injustice before making the connection to foodrelated public health issues and the food industry.

\subsection{Young on Social Structures, Structural Inequality, and Structural Injustice}

Young uses the notion of social structures to discuss the institutional background that shapes individuals' abilities to act and express themselves but over which they have little control. She understands social structures as the relation of basic social positions and processes that "fundamentally condition the opportunities and life prospects of the persons located in those positions" (Young 2001, 14). This conditioning-which creates opportunities and constraints- takes place because actions and interactions in one situation that condition people in position $\mathrm{X}$ reinforce the rules and resources available for the different (inter)actions of people in positions $Y$ and $\mathrm{Z}$. The unintended consequences of this multitude of interactions often create more opportunities and constraints and also reinforce them, shaping the habits and expectations of actors, as well as partly shaping the physical conditions needed for future actions (Young 2001).

Young gives the example of unskilled female workers in Southeast Asia who move from the countryside to the city and who stand in a specific structural relation to the small entrepreneurs who employ them in the garment industry. These entrepreneurs are, in turn, structurally positioned in relation to large multinationals and exporting firms. These different structured positions offer dissimilar and unequal opportunities to the actors who hold these positions (Young 2011).

Structural inequalities arise when certain groups of people are (relatively) constrained in their freedom and material well-being as the result of the possibilities available related to their social positions; they can be compared with other groups of people who_-given their social position-have more options available and/or have easier access to certain benefits (Young 2001, 15). This does not mean that this constraint fully determines the life plans of individuals or their possibility of gaining access to certain benefits. Some relatively constrained people are lucky, and some manage to overcome these constraints through hard work. At the same time, less constrained people can be struck by bad luck or squander their bright future by making foolish decisions. Yet, Young argues that even if those more constrained 
people are able to overcome various material and cultural obstacles, they cannot be considered equal to those who faced fewer hurdles. These structural inequalities become structural injustices when

the combined operations of actions in institutions put large categories of persons under a systemic threat of domination or deprivation of the means to develop and exercise their capacities, at the same time as they enable others to dominate or give them access to an abundance of resources. Structural injustice is a kind of moral wrong distinct from the wrongful action of an individual agent or the willfully repressive policies of a state. Structural injustice occurs as a consequence of many individuals and institutions acting in pursuit of their particular goals and interests within given institutional rules and accepted norms (Young 2007, 170).

These processes can be seen as structural injustices when people are constrained to such an extent that they are put under a threat of deprivation while other actors derive significant advantages from these processes. These advantages can be understood, for instance, as a better socioeconomic position that brings with it more options and opportunities for action, as well as concrete benefits in the form of financial gain or access to resources (Young 2011).

This conception of structure and structural injustice can help us better understand how food-related health problems could constitute structural injustices, while also allowing us to think about how the industry is connected to this.

\subsection{Vulnerability to Health Deprivation as a Structural Injustice}

These social constraints also come into play in the context of food-related health issues. Although the health situation of individuals might appear to be the sole result of preferences, personal decisions, or accidents, if we zoom out and consider the relations between these various individuals and other actors in society, a 'net' of both restricting and reinforcing relationships is revealed (Young 2011). To illustrate this, let us first consider three hypothetical stories-vignettes-that will help us think about how different people are living under different social circumstances and processes that can affect their health differently.

\section{Vignette 1: Andrew}

Andrew is a young student who lives in New Orleans. His combined family income is below the national poverty line. Andrew has taken a part-time job at a fast-food restaurant, where he can eat a meal at a reduced price. Due to his long working hours and college obligations, Andrew is unable to exercise often. Given the high prices of both fresh vegetables and healthier products at the local supermarket, he often consumes instant breakfasts and ready-made meals. Andrew is significantly overweight; he suffers from diabetes and has trouble walking long distances.

Vignette 2: Brenda

Brenda is a middle-aged gastronomic journalist from Amsterdam. She has master's degrees in nutritional science and journalism and works at a leading food magazine. 
Her job allows her to rent a spacious apartment in the upper-class part of the city. Brenda can eat whatever and whenever she likes. She has every opportunity to exercise, but cares little about sports. Her health situation is dire: her BMI is high, she has high levels of cholesterol and equally high blood pressure, and she is suffering from angina pectoris.

\section{Vignette 3: Catherine}

Catherine is in her thirties and lives with her family in Stellenbosch, South Africa. Catherine's family has an average income. During her youth, Catherine was overweight and had little interests in sport and cared little about a balanced diet. Nowadays, she frequently exercises and enjoys cooking healthy meals. While she cannot afford to always buy products that are low in salt, sugar, and fat, she tries to bear in mind the nutritional value of the products she buys. Catherine has no noteworthy health problems.

\section{How Personal Choice is Constrained by Structure}

In the three examples above, it is possible to highlight various elements of personal responsibility for health. Andrew, Brenda, and Catherine have specific options available to them-e.g., choosing to eat healthier foods, running or cycling to burn-off calories, refraining from eating unhealthier food-yet they all make different choices, leading to different outcomes. Given that decisions to eat healthily and exercise ultimately depend on a personal choice, it would be possible to argue that all three of them are equally responsible for their personal health situation.

Yet such a position ignores the social contexts in which people make these choices. It fails to take into account how socioeconomic circumstances can have a negative impact on healthy dietary habits and food choices: 1) a lack of financial means restricts the opportunities to buy healthy food or to go to the gym, 2) certain rural and urban areas have limited access to fresh food, 3) specific groups of consumers have insufficient knowledge of dietary guidelines, and 4) unhealthy living habits within specific social groups can make it hard for individuals within these groups to deviate from these practices (Jarvis and Wardle 1999; Muff et al. 2010). While health differences between people are partly based on individual preferences and choices (e.g., choosing to eat fast food every day, (dis)liking going for a run) or situations involving luck or accident (e.g., genetic disposition for coronary diseases), these differences are also shaped by the way social institutions operate, what rules and norms are dominant, and how the decisions of other individuals and societal actors affect the lives of the people around them.

Although the persons in the vignettes all operate within social structures that enable them to and disable them from engaging in certain actions, in comparison with Brenda and Catherine, Andrew's possibilities for action are more restricted by social processes and circumstances. For instance, they are restricted by government policies (e.g., government subsidizing of unhealthy school lunches), by a market in which many food and beverage companies' main focus is on economic performance-which stimulates ever-increasing food consumption-and by socially 
cultivated food habits and practices that shape the consumption patterns of specific groups (Airhihenbuwa et al. 1996). This is not to say that the less healthy are not responsible for their choices, but while all three persons in the above examples have the capacity to make autonomous choices, Andrews' possibilities of making the 'healthier' choice are more constrained than those of the other two.

\section{Different Degrees of Vulnerability to Health Deprivation}

The vignettes illustrate how health-related choice by people at first glance seems to be equally distributed, but in fact can be severely biased by underlying social processes. In light of Young's work, the empirical studies on the social determinants of health (Mackenbach et al. 2016; Stronks et al. 1996) reveal that the health inequalities between socioeconomic groups can be understood as structural inequalities. While all people are in some way constrained by social structural processes, some groups of people are socially positioned in such a way that it is easier to make healthier choices and engaging in healthier behavior comes more naturally; while for others with a lower socioeconomic status, it is more difficult to opt for the healthier choice or mode of behavior.

Hence, for the latter, it is much harder to argue that their relative health position amounts to getting what they 'deserve' on the basis of their own choices. The combination of policies, individual actions, and institutional organization in the context of unhealthy food makes people in the lower socioeconomic strata more vulnerable to health deprivation in comparison with people in higher strata, which ultimately amounts to structural injustice. This is not only because the former are being put under a permanent threat to health deprivation that makes them less able to exercise their capacities, in comparison with other groups, it is an issue of structural injustice because others are, in fact, better off due to these circumstances-either because they are simply less vulnerable to, for example, the abundance of unhealthy food options, or because, as in the case of food companies, they directly benefit from the possibilities to market and sell such foods.

These considerations allow us to challenge the assumption that food-related public health issues can be seen as lifestyle diseases for which mainly the individual herself is responsible. At the same time, they also show clearly how structural injustice can be understood as a gradual concept, because the degree to which various groups are (made) vulnerable to structural health deprivation differs per group. This illustrates the point we started this article with, namely that food-related public health problems can be seen as structural injustices. Now that we have established this, we can explore how the industry is connected to these problems.

\subsection{The Food and Beverage Industry's Connection to Food-Related Public Health Issues}

The above findings have important implications for the food industry, as they provide grounds to argue that corporate actors are playing an important role in increasing the vulnerability to health deprivation of specific groups in society. 
We can make the distinction between more direct ways in which the industry is sustaining and aggravating health disparities and more intricate modes of operation that contribute to structural injustice. Examples of the former are the sales of products that evidently exceed the daily recommended intake of calories, salt, sugar, or fat in a single serving, the marketing of such products to children, and lobbying against public health regulation (Nestle 2015; Stuckler and Nestle 2012). By stalling governmental policies that aim to reduce the vulnerability to health deprivation of the population and engaging in business practices that hamper healthy consumption, the industry is contributing to structural health injustices.

Apart from these more explicit, morally questionable actions, there are several other business practices that do not seem to be morally problematic on the surface but do impact the vulnerability to health deprivation of those in society who are worse off. For instance, consider the fact that the industry is prone to selling cheap, highly processed food products. Given that poorer consumers often experience a lack of control over their lives and have less money to spend, they are less likely to resist buying these products than people who are more well-off (cf. Marmot and Wilkinson 1999). Consider that in many places in the world there are so-called food deserts - urban areas and neighborhoods in which food stores that offer healthier consumption options are largely absent (Hilmers, Hilmers, and Dave 2012). These neighborhoods are commonly inhabited by groups of people with a lower socioeconomic status, who often lack the time or the opportunity to travel to a different kind of venue in another neighborhood. Even if they could travel, the healthier option might simply be too expensive. Moreover, dominant marketing practices in the industry disproportionally affect the less well-off consumers. While businesses have marketing tools that allow them to promote particular products to specific groups, they are often hesitant to market healthier products to less well-off consumers as these groups are less likely to buy these products (Chandon and Wansink 2012; personal communication from a leading food retailer). Ultimately, these practices sustain social norms and societal processes that contribute to the health deprivation of already marginalized groups in society, and thus contribute to a greater vulnerability to food-related diseases.

Finally, the fact that many people are vulnerable to consuming unhealthy food too often and in too high a quantity ultimately benefits the companies that produce and sell those foods. It might be too simple to just hold the food industry responsible for how modern societies have developed into obesogenic environments, but one cannot deny that the industry is benefiting from this.

In this section, we have argued that food-related health deprivations should not be reduced to a matter of individual (consumer) choice and responsibility, but that these involve what Iris Marion Young calls structural injustices, in which actions and practices of different parties lead to societal circumstances that result in systematic deprivation for some and benefits for others. The food industry is one of several key actors in this, being connected both in terms of its causal contributions to unhealthy practices as well how it benefits from them. How should we evaluate this role from an ethical perspective? What are the implications for corporate responsibility? 


\section{SOCIAL CONNECTION TO STRUCTURAL INJUSTICE: EXPANDING THE SCOPE OF CORPORATE RESPONSIBILITY IN THE FOOD INDUSTRY}

In her work on responsibility for justice, Young (2011) develops a theory of responsibility for dealing with instances of structural injustice. As these injustices do not come about because of some actor's intentional or unintentional violation of moral or legal rules - but are the result of many individuals, organizations, firms, and institutions who are (mostly) acting within accepted rules and norms-Young argues that blame and fault are not the appropriate terms to understand this particular responsibility. She suggests we need a different, guiltless concept of responsibility to think about what we should do in regard to unjust structures (Young 2011).

She sets this out in her social connection model of responsibility (Young 2011). The social connection model holds that actors

bear responsibility for structural injustice because they contribute by their actions to outcomes that produce unjust outcomes. Our responsibility derives from belonging together with others in a system of interdependent processes of cooperation and competition through which we seek benefits and aim to realise projects (Young 2011, 105).

The idea is that actors that operate in (global) unjust political, social, and economic processes have a shared responsibility by virtue of participating in these structures. Structural injustices are not caused by a single actor but by a multitude of actors, and as such responsibility does not fall to one actor but rather to all actors that are participating in these structures whom are directly and indirectly connected to harm and injustice. All connected actors-e.g., governments, consumers, families, schools, nongovernmental organizations (NGOs), and firms-share a guiltless responsibility to address these harms. Rather than looking back in order to blame specific actors, the social connection approach puts forth the question, Who are best placed to address these injustices? This allows for a more forward-looking approach to responsibility that puts working toward a solution to these problems at its center (cf. Young 2006, 2011).

We hold that this shared responsibility should not be understood as a zero-sum game. It is not the case that if one actor decides to discharge its responsibility this could absolve other actors from taking their share of responsibility. There is no 'responsibility pie' that is to be divided among all connected actors, where if one actor takes a large chunk of the pie, this automatically leaves less responsibility for the remaining actors. So when, for instance, the national government launches a new public health program to counter obesity, this does not lower the degree of responsibility of individual consumers or corporate actors, nor does governmental responsibility shrink the moment the industry takes greater responsibility for public health (Verweij 2014; Verweij and Dawson 2019). Ultimately, this responsibility should be understood as a political responsibility, for it can only be discharged by engaging in collective action with other connected actors (Young 2011).

Taking responsibility and addressing injustice in our case focuses on how health deprivations and inequalities among social groups can be prevented and how the 
situation of those vulnerable to health deprivation can be mitigated and improved. In the previous section, we established how the food industry is connected to the rise of NCDs and corresponding structural injustices, and as such the argument could be made that-following the social connection model of responsibility-actors in the food and beverage industry have a political responsibility to address this (cf. Schrempf 2014).

While intuitively plausible, we hold that an important theoretical argument is missing, for Young does not clearly substantiate the claim that a connection to structural injustice also implies a responsibility to take action. In her work, she briefly touches upon three kinds of connection, namely an existential connection, which exists by virtue of belonging together in a social system; a causal connection, which entails a mediated causal contribution to structural injustice; and a dependent connection, which refers to how our actions are dependent on other actors (McKeown 2014; Young 2011). ${ }^{4}$ When looking at the case of the food industry, this means that firms have a responsibility to address structural injustices because 1) they are part of a social system in which food-related structural injustices exist, 2) through their products and business practices they are an enabling cause for foodrelated health injustices, and 3) in their actions they depend on other actors (e.g., suppliers, but also vulnerable consumer groups).

However, several scholars point out that the normative relevance of these connections is underspecified. Merely pointing out connection does not provide a full-fledged normative argumentation why this would also entail a political responsibility to address structural injustices (cf. Barry and Ferracioli 2013; Owen 2013; Reiman 2012). So, for our case, this means we need to assess what moral principles can substantiate and explain how connection to nutrition-related structural injustices can ground food companies' responsibility to address these injustices.

Apart from the unclear normative force of connection, there is the question of the scope of political responsibility and what taking this responsibility would mean in practice. Young points out that even though having a responsibility because of social connection is a shared responsibility, it is not an equal responsibility. Those who share responsibility should take action but have to decide what is realistic based on their social position in the system, taking into account their particular abilities, circumstances, and (accrued) advantages. While she does touch upon certain parameters to guide our reasoning regarding attributing responsibilities for structural injustices (e.g., power, privilege, interest, and collective ability), these parameters are not clearly defined nor do they say anything about what this would entail in corporate practice (cf. Neuhäuser 2014; Owen 2013).

Hence, in order to identify what kind of corporate action would be required of food firms to address these injustices, we first need to know what counts as a normative significant connection that would generate a responsibility for structural

\footnotetext{
${ }^{4}$ While it might be worthwhile to explore Young's different and sometimes conflicting understandings of connection in more detail, it goes beyond the scope this particular article. For a more elaborate exploration of Young's different understandings of existential, causal, and dependent connection and their conceptual (in)compatibility, see McKeown (2014).
} 
justice. In the next subsections, we expand on Young's theory and clarify how the social connections at hand imply moral obligations and what these could mean for the food industry.

\subsection{Why Social Connection Implies a Corporate Responsibility to Address Structural Injustices}

We have argued that food companies are socially connected to the growing prevalence of noncommunicable diseases that are especially dominant under socioeconomically more vulnerable groups. Young claims that such social connections imply a responsibility to respond to structural injustice. In order to answer the question of what can be reasonably expected of food companies, we first need to explore how their connections to health problems support a moral obligation to address such problems.

A first moral ground arises as we emphasize how people are, in fact, deprived or at risk of becoming deprived of health. The appropriate response to suffering, for any actor that is interacting, living, or operating in a moral community, is beneficence - to relieve or prevent suffering. This is a basic responsibility present in most - if not all — ethical theories, from utilitarianism and Kantian deontology to virtue ethics and existentialist theories of ethics (cf. Singer 1972; Levinas 1969; Gert 2004). We believe that the extent to which one has an obligation of beneficence largely depends on the extent of suffering and one's possibilities to take it away or prevent it. When it comes to food-related health deprivations, such a duty of beneficence also befalls actors in the food industry, and arguably the food and beverage industry is more in a position to contribute to the prevention of these diseases rather than to find a cure.

Yet, this remains a very general responsibility that is derived from being part of a system and operating in it. When we look more closely at the social connections between a food producer or retailer and possible health deprivations, there is reason to see obligations of beneficence to be more specific. For example, it may be that certain vulnerable groups are depending for their nutrition on specific corporate agents-think of a discount supermarket in a food desert. This relation of dependency offers support for various moral concerns. Relations of dependency are often seen as creating special moral bonds that go beyond general beneficence, either because they involve a specific caring role (as in the case of parents towards their children) or because the depending party is particularly vulnerable to possible negative consequences of what the other does or does not do. Strong dependencies also create possibilities of exploitation or domination-and precautions to avoid such exploitation could be justified as a matter of non-maleficence and justice (cf. Valdman 2008; Young 1990).

Another normative consideration that would ground a political responsibility in the light of connection to structural injustice is fairness. This is specifically relevant where actors (for example, food companies) are also linked to structural injustice in the sense that they directly or indirectly benefit from those circumstances. If many share responsibility for such circumstances to occur and sustain, and some are 
reaping benefits of the situation, it is fair to assume that those have a special responsibility to contribute to the prevention or resolution of those problems (cf. Butt 2007; Meyers 2004; Miller 2012). Fairness would also be a ground for arguing that those who have a greater causal role in the structural injustice also have a greater responsibility to respond to it.

Upon establishing that social connection implies a responsibility to address these injustices, we can hold that firms have a responsibility to address structural health injustices. But the question remains: What would this imply for different actors in the food industry in their daily practices?

\subsection{Implications for the Scope of Corporate Responsibility in the Food and Beverage Industry}

We propose three criteria - capacity, benefit, and vulnerability - in order to answer three questions: 1) What can different companies do?,2) Which companies should do more?, and 3) Which consumer groups should be given priority? Rather than focusing on one set of actors (for instance, the fast-food industry), taking into account these three criteria enables differentiation of degrees of responsibility among the actors in the industry (from the multinational food producer to the supermarket and the local food kiosk) and the type of actions that could be required of them.

\section{Capacity: What Can Different Companies Do?}

When determining the kind of responsibility an actor has, a relevant consideration is whether it has the ability to address specific injustices. Whether the actor is well placed to take responsibility depends on the specific set of capacities it has (Miller 2012). In the context of business, there are certain corporate capacities that are the most relevant regarding influencing and reducing the impact of food-related public health issues. Corporate capacity is a broad concept, but we can think of different elements, such as financial performance, company size, market position, and the type of business involved, to help determine the capacity of a corporate actor to affect structural health deprivation.

The first element that is central to determining the capacity of the firm is the company's financial performance. Because firms have an economic responsibility that they have to meet, next to their social responsibilities, corporate actors will always have to find a balance between having responsibility for the survival of the company and having a responsibility to society (Steinmann and Löhr 1996). When a company is facing losses and is struggling to survive in the market, it will become harder to take some social responsibility than when it is making substantial profits. This does not mean that social considerations should fully fade into the background; one would always wonder, for instance, to what extent it is essential for the survival of the firm to pay the CEO over $\$ 14$ million a year or to hire a famous film star to promote its product; the same money could be diverted to societal goals. Nevertheless, in general, it can be argued that the greater the revenues and profit of a company, the more likely it is that it will be able to divert money to addressing situations of health deprivation the company is connected to. 
Related to this are the market position and the size of the company. The market position of the company codetermines the extent to which it is constrained when taking action. It might be easier for the market leaders in the food and beverage industry (e.g., Unilever, Nestlé, Heinz, Mondelēz, or PepsiCo) to develop pro-health activities and engage in more risky market behavior (introducing new, healthier products, changing certain popular, unhealthy products) than smaller companies that have recently entered the market, which face higher start-up costs and greater economic risks. Consider, for instance, Ahold Delhaize, which occupies a leading position in the global retail market. Combining the high financial performance of the firm with the fact that it has many stores spread over three continents creates room to experiment with the sales of new, healthier food products and to try out novel marketing and nudging strategies to reduce the risks of health deprivation. Furthermore, the market frontrunners have the capacity to realize societal change, as they can urge public and private actors to take collective action. They can take the lead in shaping the discourse on public and private food and health governance, for instance by creating sector-wide, (public-) private cooperation on healthy food (similar to the creation of the Forest Stewardship Council and the Round Table for Sustainable Palm Oil) or even by lobbying the government and supranational organizations for stronger health regulations (rather than lobbying against it).

Finally, the type of business is relevant in determining the capacity of a firm to take responsibility. The specific kind of skills and tools of a particular firm largely determines what it can do to remedy health deprivation. It therefore makes sense that food producers mainly focus on the product level, such as the reformulation of existing products (e.g., improving nutritional value, increasing satiety, decreasing energy availability), the development of new healthy products, and enhancing transparency concerning the nutritional value of certain products (e.g., labeling, front-of-pack nutrition information). Other types of businesses, such as kiosks, cafeterias, and supermarkets, are better placed to take responsibility by steering consumer behavior (e.g., experimenting with nudging, developing more responsible marketing practices). The top food multinationals can take action at multiple levelsmarketing and the development of products, for example — but can also conduct longterm research on the effect of their products, develop new marketing strategies, and monitor consumer behavior as well as foster private and public-private cooperation to reduce vulnerability to health deprivation (Astrup et al. 2006; Tempels, Verweij, and Blok 2017).

\section{Benefit: Which Companies Should Do More?}

As pointed out in the previous section, structural injustice is not only a matter of the presence of inequalities in the social position of groups; it also involves how other actors benefit from the dire situation others are in. In the context of health deprivation, groups of persons might not necessarily reap financial benefits from the health deprivation of other groups in society, yet many corporate actors in the food and beverage industry do. As Miller (2012) and Butt (2007) point out, benefiting from such injustices creates a responsibility to address these injustices. 
Given that we are trying to determine which companies could do more, it makes sense to assess the extent to which specific firms are benefitting from these injustices. It would be a simplification of reality to merely assess the revenues of each food and beverage company, as firms offer different products and employ different strategies to promote their products. We argue that firms that mainly sell unhealthy products are more likely to derive the majority of their revenue from structurally disadvantaged consumer groups, in comparison with firms that have a healthier or more balanced product portfolio, as people from lower socioeconomic groups are more likely to consume cheap, unhealthy food and beverage products (cf. Whittle et al. 2015).

The kind of product market a company is deriving its revenues from therefore becomes relevant. It matters whether a company is mainly selling fries fried in lard or sugar-laden energy drinks, or whether it is producing seaweed burgers or snacks that are low in salt, sugar, and fat. Although there are firms that produce only one type of unhealthy products, there are also many companies that offer a wide variety of products-some of which are more likely to have a negative impact on health than others. In order to say something about the degree to which these firms benefit from structural health injustice, it is relevant to assess the product portfolio of these firms, the way in which these products find their way to the market, and to whom they are being sold.

Companies should assess 1) to what extent they are selling unhealthy products, 2) to what extent these types of products make up a large part of their product catalog, 3) whether the sale of these products is being actively promoted, and 4) to what extent these products are specifically consumed by more vulnerable groups. The more a company is selling and promoting the sale of products that have a greater potency in terms of contributing to the health deprivation of groups that are already vulnerable, the greater the likelihood that the company is benefitting from injustice. This illustrates that benefiting from the vulnerable creates a stronger responsibility to take action, and the vulnerable need to be prioritized when this action is taken, as we will discuss next.

\section{Vulnerability: Which Consumer Groups Should be Given Priority?}

Taking the criterion of vulnerability into account means that a firm's responsibility for food-related public health issues is more stringent at the moment it is dealing with consumer groups that are more constrained due to their lower socioeconomic status. In line with the argument about benefitting, it is also the case that if a company's revenues are mainly derived from products sold to those groups that are vulnerable to health deprivation, this gives the company stronger reasons to contribute to strengthening the health situation of these groups.

Note that this does not imply that firms would have to engage in group-specific paternalistic behavior, such as taking away soda of the poor, while allowing the wealthy to keep drinking their sugar-laden drinks. To understand what taking into account this vulnerability to health deprivation does entail, let us imagine a large food multinational. The company is aware of socioeconomic health differences between its consumer groups and aims to effectuate its responsibility for health 
by developing new policies and practices to address the food-related health diseases its consumers are dealing with. Given that the firm's CSR possibilities are always constrained by economic considerations, the criterion of vulnerability can help prioritize the various options the company has regarding taking responsibility for health. Corporate policies that aim to improve public health should in the first place target those groups that are most vulnerable to health deprivation. This could, for example, mean that the firm would 1) start healthy innovation on products that are generally bought by people in the lower socioeconomic strata, 2) give coupons for healthier food products to people who receive social benefits, 3) prioritize sponsoring sport activities in neighborhoods where people with a lower socioeconomic status live, and 4) start experimenting with pro-health nudging and pro-health marketing in these neighborhoods. ${ }^{5}$

Now, one could argue that the most effective solution might be to limit the sales of unhealthy products in neighborhoods with high concentrations of consumers with a lower socioeconomic status in general, or simply to limit the sales of these products in particular. However, we hold that such approaches would disproportionally and negatively affect consumer equality as well as leave little room for consumer preference. In order to avoid possible corporate paternalism, the strategies discussed above create a more positive, equal, and inclusive approach to corporate responsibility for health. They should take into account the vulnerability of certain groups but also reward these consumers with a healthier product rather than punishing them by removing choice.

The brief elaboration of these criteria reveals how corporate responsibility for food-related public health issues can take shape. The above examples are not allencompassing, but they can help guide our intuition concerning which actors in the food industry can do what, which of them should do more, and which consumer groups should be given priority. In what way this can viably take shape in daily corporate practice should be further explored in empirical research, but this discussion reveals what the pathways for taking corporate responsibility for foodrelated public health issues could look like.

\section{THEORETICAL AND PRACTICAL IMPLICATIONS}

The discussion above shows how taking into account structural injustices has important implications for our understanding of corporate responsibility. Our approach expands the notion of corporate responsibility: we point out how corporate responsibility should go beyond living up the law and adhering to principles of ordinary morality such as nonmaleficence and respect for (consumer) autonomy by showing how firms also have a forward-looking political responsibility for the

\footnotetext{
5 There is ample discussion on the possible problematic aspects of nudging in regard to autonomy and freedom of choice in the public sector (Grüne-Yanoff 2012; Sunstein 2014), but whether this is problematic within the context of the private sector has yet to be explored. Although this topic requires further reflection, it goes beyond the scope of this article.
} 
structural injustices that arise out of the social processes in the global system in which they operate.

Political responsibility for justice complements the basic moral and legal responsibilities of corporate actors. All corporate actors that are connected to nutritionrelated structural injustices - implying both a fully law-abiding supermarket chain, as well as a blameworthy fast-food company-have to take action to change the social structures that facilitate and perpetuate structural health deprivation. This means that this political responsibility might be conceived as a virtue, as it requires firms to assess what operating as a responsible actor in the global system entails and how they can practice this while balancing other moral considerations (cf. McKeown 2014). This makes discharging this responsibility actor-specific and more open-ended. Note that taking political responsibility can involve supporting stricter legal regulation (for instance, companies lobbying governments for stricter food safety laws). This could put certain undesirable business practices within a legal framework, allowing these food practices to be more strictly controlled though governmental rule-setting and regulation.

This conceptualization of political responsibility is not only relevant for the food industry, it also applies to responsibilities that firms have for other structural problems, such as the structural harms of gun violence or the exploitation of minorities in marketing campaigns (Brenkert 1998, 2000).

While social connection to structural injustice implies an ongoing responsibility to contribute to a more just society, the criteria of vulnerability, benefit, and capacity help to focus CSR practices in specific sectors and contexts. Even though in a globalized business environment firms are connected to many instances of injustice, it is possible to assess what particular injustices firms have a closer connection to. For instance, although it is morally laudable that Coca-Cola focuses part of its CSR activities on the dire labor conditions of construction workers in Dubai (Vara 2014), it might be more appropriate to focus on the negative impacts its own products and core business activities have on global public health. In a similar fashion, the connection between a supermarket and health deprivation is more stringent when it is operating in a food desert with vulnerable low-income residents (making it more likely that the supermarket will benefit from the health deprivation of its consumers) compared to when this same firm is operating in a healthy and wealthy neighborhood. In addition, depending on the capacities and position of their firm in the market, every entrepreneur, CSR manager, or CEO can make an assessment of what kind of actions would be more suitable. A local entrepreneur can assess whether it is possible to switch to healthier products, while the CEO of a large food multinational can take the lead in lobbying against child marketing.

These criteria can also be applied to different kinds of industries, such as the garment industry or the weapons industry. In the case of the latter, it might be morally laudable for these firms to fund public playgrounds, but given their social connection to gun violence, it might be more fitting to see how changes in the design, advertising, and distribution of their core product can curb this impact (Brenkert 2000). 


\section{CONCLUSION}

The responsibility of the food and beverage industry for the rise of noncommunicable diseases remains a controversial topic. Yet by drawing on the work of Iris Marion Young, we show that corporate actors in the food and beverage industry have a responsibility to address the structural injustices in food-related NCDs, and we provide additional criteria to help clarify the scope and content of corporate action regarding public health for different corporate actors in the sector.

This article has three key contributions. First, we show that the unequal distribution of food-related public health problems among social groups in society can be understood as a structural injustice. We explain how groups with a lower socioeconomic status can be structurally constrained in their opportunities to make healthy decisions, which makes them more vulnerable to health deprivation in the form of food-related diseases, in comparison with groups in the upper strata of society. Structural injustice is a gradual concept, depending on the extent to which different groups of people are more or less vulnerable to deprivation. Food-related public health problems are a structural injustice for those groups that are most limited in their action opportunities, but other social groups may well be free from such constraints.

Second, our study contributes to the debate on the grounds and scope of corporate responsibility by showing how corporations can also have guiltless political responsibility for structural injustices. Furthermore, the criteria of capacity, benefit, and vulnerability provide guidance regarding what taking this responsibility can entail for different types of firms working with different consumer groups. These criteria are not only useful when talking about public health issues but can also help to guide corporate action in other situations involving structural injustice (e.g., sweatshop labor and discrimination on the basis of race or gender).

Finally, this study contributes to connecting the debates on business ethics and public health ethics by providing a justification why corporate actors in the food and beverage industry have a broader positive responsibility for addressing food-related public health issues. We show how the food and beverage industry, through its business activities, is sustaining and enhancing the vulnerability to health deprivation of specific groups in society. Taking responsibility for food-related public health issues should ideally take into account to what extent a company is dealing with consumer groups that are more structurally constrained. This has implications for CSR programs in the food and beverage sector, as it can be seen as a call for more tailor-made approaches that are specific to the context a company is operating in and the kind of consumers it is dealing with.

The food and beverage industry plays a role in structural health injustices and this expands the scope of corporate responsibility for health beyond merely living up the law and adhering to basic moral principles, such as nonmaleficence and respect for consumer autonomy. In practice, this means food firms have a responsibility to go beyond providing information on a healthy lifestyle and providing healthy food options. Justly and earnestly engaging in corporate responsibility for health entails that businesses should work toward limiting their impact on the health deprivation of vulnerable groups in society and-together with governments, IGOs, NGOs, and consumers-should work toward remedying food-related public health issues. 


\section{ACKNOWLEDGEMENTS}

We wish to thank Beatrijs Haverkamp, Teunis Brand, Eva Groen-Reijman, and Morten Byskov for their helpful remarks and valuable comments. We are grateful to the two anonymous reviewers and to Business Ethics Quarterly editors Denis Arnold and Bruce Barry for their very detailed and insightful feedback.

\section{REFERENCES}

Adams, Ronald. 2005. "Fast Food, Obesity, and Tort Reform: An Examination of Industry Responsibility for Public Health.” Business and Society Review 110 (3): 297-320.

Airhihenbuwa, Collins O., Shiriki Kumanyika, Tanya D. Agurs, Agatha Lowe, David Saunders, and Christiaan B. Morssink. 1996. "Cultural Aspects of African American Eating Patterns." Ethnicity \& Health 1 (3): 245-60.

Arnold, Denis G. 2013. "Global Justice and International Business." Business Ethics Quarterly 23 (1): 125-43.

Astrup, Arne, M. W. L. Bovy, K. Nackenhorst, and A. E. Popova. 2006. "Food for Thought or Thought for Food?-A Stakeholder Dialogue around the Role of the Snacking Industry in Addressing the Obesity Epidemic." Obesity Reviews 7 (3): 303-12.

Barnhill, Anne. 2016. "I'd like to Teach the World to Think: Commercial Advertising and Manipulation." Journal of Marketing Behavior 1 (3-4): 307-28.

Barnhill, Anne, Katherine F. King, Nancy Kass, and Ruth Faden. 2014. "The Value of Unhealthy Eating and the Ethics of Healthy Eating Policies." Kennedy Institute of Ethics Journal 24 (3): 187-217.

Barry, Christian, and Luara Ferracioli. 2013. "Young on Responsibility and Structural Injustice." Criminal Justice Ethics 32 (3): 247-57.

Beauchamp, Tom L., R. M. Hare, and Barry Biederman. 1984. "Manipulative Advertising [with Commentaries]." Business \& Professional Ethics Journal 3 (3/4): 1-30.

Bowie, Norman E. 1999. Business Ethics: A Kantian Perspective. New York: Wiley.

Brenkert, George G. 1998. "Marketing to Inner-City Blacks: Powermaster and Moral Responsibility." Business Ethics Quarterly 8 (1): 1-18.

Brenkert, George G. 2000. "Social Products Liability: The Case of the Firearms Manufacturers." Business Ethics Quarterly 10 (1): 21-32.

Brownell, Kelly D., and Kenneth E. Warner. 2009. "The Perils of Ignoring History: Big Tobacco Played Dirty and Millions Died. How Similar Is Big Food?" The Milbank Quarterly 87 (1): 259-94.

Butt, Daniel. 2007. “On Benefiting from Injustice.” Canadian Journal of Philosophy 37 (1): 129-52.

Buzby, Jean C., and Paul D. Frenzen. 1999. "Food Safety and Product Liability." Food Policy 24 (6): 637-51.

Carsons, T.L. 2009. "Deception and Information Disclosure in Business and Professional Ethics." In The Oxford Handbook of Business Ethics, edited by George G. Brenkert and Tom L. Beauchamp. Oxford: Oxford University Press.

Chandon, Pierre, and Brian Wansink. 2012. "Does Food Marketing Need to Make Us Fat? A Review and Solutions." Nutrition Reviews 70 (10): 571-93.

Childress, James F., Ruth R. Faden, Ruth D. Gaare, Lawrence O. Gostin, Jeffrey Kahn, Richard J. Bonnie, Nancy E. Kass, Anna C. Mastroianni, Jonathan D. Moreno, and 
Phillip Nieburg. 2002. "Public Health Ethics: Mapping the Terrain.” The Journal of Law, Medicine \& Ethics 30 (2): 170-78.

Crisp, Roger. 1987. "Persuasive Advertising, Autonomy, and the Creation of Desire." Journal of Business Ethics 6 (5): 413-18.

Dorfman, Lori, Andrew Cheyne, Lissy C. Friedman, Asiya Wadud, and Mark Gottlieb. 2012. "Soda and Tobacco Industry Corporate Social Responsibility Campaigns: How Do They Compare?" PLoS Med 9 (6): e1001241.

Ebejer, James M., and Michael J. Morden. 1988. "Paternalism in the Marketplace: Should a Salesman Be His Buyer's Keeper?” Journal of Business Ethics 7 (5): 337-39.

Elliott, Charlene. 2015. “'Big Food' and 'Gamified'Products: Promotion, Packaging, and the Promise of Fun." Critical Public Health 25 (3): 348-60.

Epstein, Richard A. 2004. "What (Not) to Do about Obesity: A Moderate Aristotelian Answer." Georgetown Law Journal 93: 1361.

Fields, Scott. 2004. "The Fat of the Land: Do Agricultural Subsidies Foster Poor Health?" Environmental Health Perspectives 112 (14): A820.

Franck, Caroline, Sonia M. Grandi, and Mark J. Eisenberg. 2013. "Agricultural Subsidies and the American Obesity Epidemic." American Journal of Preventive Medicine 45 (3): $327-33$.

Freeman, R.E. 2002. "A Stakeholder Theory of the Modern Corporation." In Perspectives in Business Ethics, edited by Laura Pincus Hartman, 171-81. Boston: McGraw-Hill.

Friedman, Milton. 2009. Capitalism and Freedom. Chicago, IL: University of Chicago Press.

Gert, Bernard. 2004. Common Morality: Deciding What to Do. Oxford: Oxford University Press.

Gilmore, Anna B., Emily Savell, and Jeff Collin. 2011. "Public Health, Corporations and the New Responsibility Deal: Promoting Partnerships with Vectors of Disease?” Journal of Public Health 33 (1): 2-4.

Gostin, Lawrence O. 2008. Public Health Law: Power, Duty, Restraint. Berkeley, CA: University of California Press.

Grüne-Yanoff, Till. 2012. "Old Wine in New Casks: Libertarian Paternalism Still Violates Liberal Principles." Social Choice and Welfare 38 (4): 635-45.

Hasnas, John. 2009. "The Mirage of Product Safety." In The Oxford Handbook of Business Ethics, edited by George G. Brenkert and Tom L. Beauchamp. Oxford: Oxford University Press.

Haverkamp, Beatrijs, Marcel Verweij, and Karien Stronks. 2018. "Why Socio-Economic Inequalities in Health Threaten Relational Justice. A Proposal for an Instrumental Evaluation." Public Health Ethics 11 (3): 311-24.

Heikkurinen, Pasi, and Jukka Mäkinen. 2018. "Synthesising Corporate Responsibility on Organisational and Societal Levels of Analysis: An Integrative Perspective.” Journal of Business Ethics 149(3): 589-607.

Hilmers, Angela, David C. Hilmers, and Jayna Dave. 2012. "Neighborhood Disparities in Access to Healthy Foods and Their Effects on Environmental Justice." American Journal of Public Health 102 (9): 1644-54.

Hsieh, Nien-hê. 2017. "The Responsibilities and Role of Business in Relation to Society: Back to Basics?” Business Ethics Quarterly 27 (2): 293-314.

Jarvis, M.J., and J. Wardle. 1999. "Social Patterning of Individual Health Behaviours: The Case of Cigarette Smoking." In Social Determinants of Health, 240-55. Oxford: Oxford University Press. 
Levinas, Emmanuel. 1969. Totality and Infinity: An Essay on Exteriority, Trans. Alphonso Lingis. Pittsburgh, PA: Duquesne University Press.

Mackenbach, Johan P., Ivana Kulhánová, Barbara Artnik, Matthias Bopp, Carme Borrell, Tom Clemens, Giuseppe Costa, et al. 2016. "Changes in Mortality Inequalities over Two Decades: Register Based Study of European Countries." Bmj 353: 11732.

Marmot, M., and R.G. Wilkinson. 1999. Social Determinants of Health. Oxford: Oxford University Press.

McKeown, Maeve. 2014. "Responsibility without Guilt: A Youngian Approach to Responsibility for Global Injustice.” PhD thesis, UCL School of Public Policy. http:// discovery.ucl.ac.uk/1463742/3/McKeown\%20Thesis\%20(FINAL\%2016.03.15).pdf.

Meyers, Chris. 2004. "Wrongful Beneficence: Exploitation and Third World Sweatshops." Journal of Social Philosophy 35 (3): 319-33.

Miller, David. 2001. "Distributing Responsibilities." Journal of Political Philosophy 9 (4): 453-71.

Miller, David. 2012. National Responsibility and Global Justice. Oxford: Oxford University Press.

Moss, Michael. 2013. Salt, Sugar, Fat: How the Food Giants Hooked Us. New York: Random House.

Muff, Christine, N. Dragano, K.-H. Jöckel S. Moebus S. Möhlenkamp, R. Erbel K. Mann, and J. Siegrist. 2010. "Is the Co-occurrence of Smoking and Poor Consumption of Fruits and Vegetables Confounded by Socioeconomic Conditions?" International Journal of Public Health 55 (4): 339-46.

Nestle, Marion. 2013. Food Politics: How the Food Industry Influences Nutrition and Health, vol. 3. Berkeley, CA: University of California Press.

Nestle, Marion. 2015. Soda Politics: Taking on Big Soda (and Winning). Oxford: Oxford University Press.

Neuhäuser, Christian. 2014. "Structural Injustice and the Distribution of Forward-Looking Responsibility." Midwest Studies In Philosophy 38 (1): 232-51.

$\mathrm{Ng}$, Marie, Tom Fleming, Margaret Robinson, Blake Thomson, Nicholas Graetz, Christopher Margono, Erin C Mullany, et al. 2014. "Global, Regional, and National Prevalence of Overweight and Obesity in Children and Adults during 1980-2013: A Systematic Analysis for the Global Burden of Disease Study 2013.” The Lancet 384 (9945): 766-81.

Owen, David. 2013. "Responsibilities of Justice. Reading Young on Political Responsibility and Structural Injustice." In Zwischen Demokratie Und Globaler Verantwortung, 93-110. Broschiert: Nomos Verlagsgesellschaft mbH \& Co. KG.

Palmer, David, and Trevor Hedberg. 2013. "The Ethics of Marketing to Vulnerable Populations." Journal of Business Ethics 116 (2): 403-13.

Reiman, Jeffrey. 2012. "The Structure of Structural Injustice: Thoughts on Iris Marion Young's 'Responsibility for Justice."” Edited by Iris Marion Young. Social Theory and Practice 38 (4): 738-51.

Rothstein, Mark A. 2002. "Rethinking the Meaning of Public Health." The Journal of Law, Medicine \& Ethics 30 (2): 144-49.

Scherer, Andreas Georg, Andreas Rasche, Guido Palazzo, and André Spicer. 2016. "Managing for Political Corporate Social Responsibility: New Challenges and Directions for PCSR 2.0." Journal of Management Studies 53 (3): 273-98.

Schrempf, Judith. 2014. "A Social Connection Approach to Corporate Responsibility The Case of the Fast-Food Industry and Obesity.” Business \& Society 53 (2): 300-332. 
Shelley, Donna, Gbenga Ogedegbe, and Brian Elbel. 2014. "Same Strategy Different Industry: Corporate Influence on Public Policy.” American Journal of Public Health 104 (4): e9-e11.

Sher, Shlomo. 2011. "A Framework for Assessing Immorally Manipulative Marketing Tactics." Journal of Business Ethics 102 (1): 97-118.

Singer, Peter. 1972. "Famine, Affluence, and Morality." Philosophy \& Public Affairs, 229-43. Smith, Elizabeth. 2012. "Corporate Image and Public Health: An Analysis of the Philip Morris, Kraft, and Nestle Websites." Journal of Health Communication 17 (5): 582-600.

Steinmann, Horst, and Albert Löhr. 1996. "A Republican Concept of Corporate Ethics." In Europe's Challenges: Economic Efficiency and Social Solidarity, edited by Sabine Urban, 21-60. Wiesbaden: Springer Science \& Business Media.

Stronks, Karien, H. Dike Mheen, Casper WN Looman, and Johan P. Mackenbach. 1996. "Behavioural and Structural Factors in the Explanation of Socio-Economic Inequalities in Health: An Empirical Analysis." Sociology of Health \& Illness 18 (5): 653-74.

Stuckler, David, Martin McKee, Ebrahim Shah, and Basu Sanjay. 2012. "Manufacturing Epidemics: The Role of Global Producers in Increased Consumption of Unhealthy Commodities Including Processed Foods, Alcohol, and Tobacco." PLOS Medicine 9 (6).

Stuckler, David, and Marion Nestle. 2012. "Big Food, Food Systems, and Global Health." PLOS Med 9 (6): e1001242.

Sunstein, Cass R. 2014. Why Nudge?: The Politics of Libertarian Paternalism. New Haven, CT: Yale University Press.

Sunstein, Cass R. 2016. "Fifty Shades of Manipulation." Journal of Marketing Behavior 1 (3-4): 213-44.

Tempels, Tjidde, Vincent Blok, and Marcel Verweij. 2017. "Understanding Political Responsibility in Corporate Citizenship: Towards a Shared Responsibility for the Common Good." Journal of Global Ethics 1 (13): 90-108.

Tempels, Tjidde, Marcel Verweij, and Vincent Blok. 2017. "Big Food's Ambivalence: Seeking Profit and Responsibility for Health." American Journal of Public Health 107 (3): 402-6.

Valdman, Mikhail. 2008. "Exploitation and Injustice." Social Theory and Practice 34 (4): 551-72.

Vara, Vauhini. 2014. “Coca-Cola's Happiness Machines.” The New Yorker, May 15. https:// www.newyorker.com/business/currency/coca-colas-happiness-machines.

Verweij, Marcel. 2014. Curiosity and Responsibility: Philosophy in Relation to Healthy Food and Living Conditions. Wageningen: Wageningen University.

Verweij, Marcel, and Angus Dawson. 2009. “The Meaning of 'Public' in 'Public Health.”' In Ethics, Prevention, and Public Health. Oxford: Oxford University Press.

Verweij, Marcel, and Angus Dawson. 2019. "Sharing Responsibility: Responsibility for Health Is Not a Zero-Sum Game." Public Health Ethics 12 (2): 1-4.

Walters, Joanna. 2015. "Nutrition Experts Alarmed by Nonprofit Downplaying Role of Junk Food in Obesity." The Guardian, August 11, 2015. https://www.theguardian.com/soci ety/2015/aug/11/obesity-junk-food-exercise-global-energy-balance-network-coca-cola.

Whittle, Henry J., Kartika Palar, Lee Lemus Hufstedler, Hilary K. Seligman, Edward A. Frongillo, and Sheri D. Weiser. 2015. "Food Insecurity, Chronic Illness, and Gentrification in the San Francisco Bay Area: An Example of Structural Violence in United States Public Policy.” Social Science \& Medicine 143 (October): 154-61. 
Wicker, Catherine Srithong. 2015. "The Not So Sweet Surprise: Lawsuits Blaming Big Sugar for Obesity-Related Health Conditions Face an Uphill Battle." Journal of Law and Health 28: 264-307.

Yoon, Sungwon, and Tai-Hing Lam. 2013. "The Illusion of Righteousness: Corporate Social Responsibility Practices of the Alcohol Industry." BMC Public Health 13 (1): 630.

Young, Iris Marion. 1990. Justice and the Politics of Difference. Princeton, NJ: Princeton University Press.

Young, Iris Marion. 2001. "Equality of Whom? Social Groups and Judgments of Injustice." Journal of Political Philosophy 9 (1): 1-18.

Young, Iris Marion. 2006. "Responsibility and Global Justice: A Social Connection Model." Social Philosophy and Policy 23 (1): 102-30.

Young, Iris Marion. 2007. Global Challenges: War, Self-Determination and Responsibility for Justice. Cambridge: Wiley.

Young, Iris Marion. 2011. Responsibility for Justice. Oxford: Oxford University Press.

TJidDe Tempels works at the Faculty of Philosophy, Theology, and Religious Studies and the Institute for Management Research at Radboud University (The Netherlands). In 2019, he received his $\mathrm{PhD}$ in philosophy at Wageningen University with a specialization in ethics. His main research interests are business ethics, theories of deliberative democracy, applied ethics, corporate social responsibility, and international governance. As a researcher at the intersection of political philosophy and business ethics, he investigates the responsibilities of firms for local, national, and global injustices.

VINCENT BLOK is associate professor at the Business Management and Organisation Group and the Philosophy Group at Wageningen University (The Netherlands). In 2005, he received his $\mathrm{PhD}$ in philosophy at Leiden University with a specialization in philosophy of technology. Together with a research group of three postdocs and six PhD students, Blok is involved in several (European) research projects at the crossroads of business ethics, philosophy of technology, and responsible innovation. His books include Ernst Jünger's Philosophy of Technology: Heidegger and the Poetics of the Anthropocene (Routledge, 2017). Blok's work has appeared in, amongst others, the Journal of Business Ethics, Business \& Society, Environmental Values, and Business Ethics: A European Review.

MARCEL Verweis holds the chair of philosophy at Wageningen University (The Netherlands). Before Verweij came to Wageningen, he worked as a philosopher and ethicist at Utrecht University, the University of Amsterdam, and the University Medical Centre Nijmegen and as visiting scholar at the universities of Stellenbosch, Keele, and the London School of Hygiene and Tropical Medicine. His research and teaching cover a very broad area in applied philosophy and ethics, including animal ethics and business ethics, but his primary focus is public health. Together with Angus Dawson (University of Sydney) he initiated public health ethics as a new area of study in moral philosophy. They are founding editors in chief of Public Health Ethics, a journal published by Oxford University Press that is now the center of a flourishing interdisciplinary scientific field. 